\title{
SEKILAS TENTANG BEBERAPA JENIS IKAN HIAS AIR TAWAR YANG DILARANG MASUK KE INDONESIA
}

\author{
Bambang Priono*) dan Darti Satyani** \\ *) Pusat Penelitian dan Pengembangan Perikanan Budidaya \\ Jl. Ragunan 20, Pasar M inggu, Jakarta Selatan 12540 \\ E-mail: info@ cria.indosat.net.id \\ *) Balai Riset Budidaya Ikan Hias \\ Jl. Perikanan 13, Pancoran Mas, Depok
}

\begin{abstract}
ABSTRAK
Sebagai negara yang kaya akan keragaman hayati khususnya biota perikanan air tawar, memberikan peluang usaha yang sangat baik, di antaranya usaha budidaya ikan hias. Jenis-jenis ikan hias air tawar yang diusahakan jumlahnya sangat banyak dan beragam, baik yang berasal asli Indonesia maupun introduksi dari negara lain. Perolehan nilai ekonomi dari usaha ikan hias cukup besar sehingga mengakibatkan terjadinya perdagangan ikan hias yang kadang tidak memperhatikan aspek kelestariannya di masa mendatang. Akhir-akhir ini banyak muncul berbagai jenisikan hias air tawar impor yang secarailmiah ikan-ikan tersebut dapat merugikan kesinambungan usaha ikan hias. Para pengusaha seolah melupakan bahwa pemerintah telah mengeluarkan peraturan mengenai jenis-jenis ikan yang dilarang masuk keIndonesia. Untuk itu, tulisan ini sengaja dilakukan agar para pelaku menyadari betapa berbahayanya membudidayakan ikan-ikan hias impor yang termasuk kategori dilarang.
\end{abstract}

\section{KATAKUNCl: ikan hias air tawar, kelestarian, ikan yang dilarang}

\section{PENDAHULUAN}

Dunia yang saat ini telah mengglobal akibat canggihnya berbagai macam teknologi, baik informasi, transportasi maupun bisnis membuat semua yang ada di dunia ini seolah dekat dengan kita. Demikian pula yang terjadi pada ikan hias khususnya air tawar merupakan mata dagangan yang sudah mengglobal. Beratus jenis diperjualbelikan, dipelihara, ditangkarkan oleh para pedagang, hobiis, maupun peternak di seluruh dunia. Eksportir dan importir dari setiap negara membawa masuk dan keluar ikan-ikan untuk diperdagangkan. Perputaran uang yang miliaran bahkan mungkin triliunan rupiah beredar mulai dari negara pemilik ikan yaitu produsen sampai ke konsumen di belahan bumi lainnya.

Banyak kepentingan yang masuk dalam bisnis ini. Para pedagang tentu berpikir untung rugi saat masuk ke khasanah yang namanya jual beli ikan ini. Apapun akan dilakukan untuk mendapatkan keuntungan sebesarbesarnya. Ikan dari manapun akan diburu bila itu akan menguntungkan dan mendatangkan uang.

Sebaliknya para hobiis akan berpikir lain, keuntungan, kesenangan hati dan batin menjadi prioritas. Berburu ikan yang lagi tren dan eksotik akan dilakukan walaupun mahal harganya. Uang keluar sering tidak diperhitungkan, yang penting adalah senang dan senang. Apalagi apabila sudah masuk ke komunitas hobiis, ada rasa bangga dan gengsi di sana bila mempunyai ikan yang lagi tren.

Dampak dari semua ini memang menakjubkan. Positif, karena uang yang beredar akan dapat dinikmati oleh para pelaku yang tentu saja para pekerja sehingga dapat menjadikan lapangan keja untuk cari nafkah. Pengaruh lain yang signifikan adalah masuknya devisa ke negara dari para eksportir ikan ini. Namun demikian dampak negatifnya juga tak kurang banyaknya. Pertama adalah makin banyaknya permintaan maka makin terkurasnya sumberdaya ikan. Setiap tahunnya mungkin ada saja ikan alam yang punah dari muka bumi ini akibat terkuras oleh adanya penangkapan selain perusakan lingkungan tadi. Sebagai contoh ikan-ikan jenis Betta, Black Shark yang dulu di perairan Pulau Jawa ada sekarang sudah jarang atau malah sudah tidak bisa ditemukan lagi. Balashark di Sumatera sudah jarang ada, demikian pula beberapa Rasbora sudah susah dicari (Satyani et al., 2002).

Dampak yang lain lagi dari peredaran ikan adalah masuknya ikan-ikan introduksi yang semakin banyak. Dari list para eksportir jenis ikan yang di ekspor dari alam atau penangkapan dari perairan dengan ikan introduksi yang diternak oleh para peternak, ikan alam ini lebih sedikit. Yang berarti jenis introduksi yang masuk jelas jauh lebih banyak. Dan ini akan memberikan konsekuensi 
yang juga cukup besar. Dibalik keuntungan secara ekonomi ada dampak lain yang akan terjadi yaitu keseimbangan ekosistem perairan yang terganggu.

\section{DAMPAK NEGATIF IKAN INTRODUKSI}

Mungkin benar bahwa ikan hias adalah ikan akuarium atau ikan peliharaan yang tidak mudah untuk keluar dari rumah dan masuk ke perairan (Kottelat et al., 1995). Tetapi dalam kenyataannya tidaklah demikian. Para peternak yang tentu saja berambisi untuk dapat memproduksi ikan secara besar-besaran terutama ikan yang berukuran besar seperti Red Tail Catfish, Tiger Catfish, Aligator dengan tempat terbatas menempatkan induk-induknya di jaring apung di danau. Tentu kemungkinan untuk lepas ke perairan akan amat tinggi.

Tidak akan dipungkiri pula ikan-ikan yang di dalam kolam tertutup, dengan kemungkinan maupun hampir dipastikan bahwa di Jakarta setiap tahun kebanjiran, ikan akan ikut hanyut ke perairan apalagi memang yang punya ikan-ikan ini kebanyakan adalah peternak dan hobiis di Jabodetabek.

Ada dua hal yang mungkin bisa terjadi apabila mereka lepas dari tempat pemeliharaan yaitu mati karena tidak cocok dengan habitat dan kurang pakan. Atau bila kemungkinan kedua yang terjadi yaitu mereka hidup tentu sangat mengganggu. Kebanyakan ikan-ikan ini adalah karnivora berat yang dapat dibayangkan seluruh ikan perairan akan habis dimakannya (Paysan, 1975). Apalagi bila ikan tersebut ganas, piranha misalnya akan sangat merugikan dan membahayakan perairan.

Mungkin tidak semua orang tahu bahwa pada tahun 1982 sudah diterbitkan oleh Menteri Pertanian Surat Keputusan No. 179/Kpts/UM/3/1982 yaitu peraturan tentang beberapa ikan yang dilarang masuk ke wilayah Republik Indonesia seperti ikan-ikan:

a. Serasalmus sp. (Piranha)

b. Vandelia sp. (Vampire catfish)

c. Lepisosteus sp. (Aligator gar)

d. Silurus alapis

e. Esox masquinongy

f. Electrophorus electricus (Electric eel)

g. Tetraodon spp. (ikan buntal)

h. Arapaima gigas (Arapaima)

Peraturan ini sudah diperbarui oleh Surat Keputusan Menteri Departemen Kelautan dan Perikanan (DKP) tahun 2009 dengan spesies atau jenis ikan yang sudah lebih jelas. Kecuali tentu untuk keperluan penelitian. Dengan izin khusus dan seharusnyalah diawasi secara ketat.
Namun demikian pada kenyataannya masih ada saja ikan larangan yang lolos dan diperjualbelikan di toko ikan. Misalkan ikan Aligator dan Arapaima. Selanjutnya bagaimana dan apa yang seharusnya dilakukan agar tidak terjadi seperti ini? Sosialisasi bagi para importir dan hobiis sebenarnya cara yang perlu dilakukan oleh DKP. Karena masuknya ikan-ikan ini mungkin disebabkan importir tidak tahu peraturan atau karena dimasukkan dengan cara ilegal untuk keuntungan yang besar. Wallahu alam!!!

\section{JENIS-JENIS IKAN HIAS YANG DILARANG DI INDONESIA}

Jenis-jenis ikan hias air tawar yang dilarang masuk ke Indonesia berdasarkan peraturan Menteri Kelautan dan Perikanan: PER.17/MEN/2009 tercantum pada Tabel 1.

Semenjak tahun 1982 sebenarnya telah dilakukan pencegahan ikan-ikan hias dari luar negeri masuk ke wilayah Indonesia yang dituangkan dalam Peraturan Menteri Pertanian tersebut di atas. Ada 5 genera dengan 30 spesies yang dilarang masuk ke wilayah Indonesia Bagaimana kita menyikapinya, setelah mengetahui dampak negatif masuknya jenis ikan-ikan tersebut ke wilayah perairan Indonesia. Sudah seharusnya peraturan tersebut tidak boleh dilanggar, dan perlu diterapkan sanksi yang lebih tegas bagi para pelaku impor ikan-ikan jenis tersebut. Karena selain membahayakan kelestarian keanekaragaman hayati juga akan berdampak pada menurunnya habitat ikan hias asli Indonesia.

\section{PRESENT STATUS IKAN-IKAN YANG DILARANG MASUK KE INDONESIA}

Saat ini di masyarakat telah banyak dan dibudidayakan ikan-ikan yang dilarang tetapi dapat secara bebas diperdagangkan di Indonesia. Berikut beberapa jenis ikan dan bahayanya apabila hal ini tidak segera ditertibkan:

- Ikan Serasalmus yaitu Piranha yang sangat ganas, merupakan predator yang berbahaya (Patterson, 1982). Saking ganasnya konon dapat membunuh manusia. Ukurannya umum hanya $20 \mathrm{~cm}$ tetapi yang besar dapat mencapai $30 \mathrm{~cm}$. Giginya yang tajam dapat merobek apa saja, terutama daging karena memang merupakan karnivora sejati. Karena ikan ini di alamnya hidup berkelompok maka hewan yang besarpun bila masuk perairan di mana kelompokan ikan ini berada pasti akan diserang ramai-ramai dan dibuat pesta oleh mereka.

- Ikan Aligator juga merupakan predator yang berbahaya. Dari nama dan bentuk badannya yang mirip buaya ini memang ikan aligator adalah pemangsa yang cukup ganas juga. Pakannya adalah binatang lain seperti ikan, 
Tabel 1. Jenis-jenis ikan hias air tawar yang dilarang masuk ke Indonesia

\begin{tabular}{|c|c|}
\hline Familia & Spesies \\
\hline Tetraodontidae (Puffer Fish) & $\begin{array}{l}\text { Colomeus psittatus (Bended Puffer) } \\
\text { Tetraodon duboisi (Ocellated Puffer) } \\
\text { Tetraodon lineatus (Nila/Globe/Fahaka Puffer) } \\
\text { Tetraodon mbu (Freshwater Puffer Fish) } \\
\text { Tetraodon miurus (Staenlypool Puffer) }\end{array}$ \\
\hline Trichomycteridae (parasitic Catfish) & $\begin{array}{l}\text { Brachioica bertonii/Paravandella oxyptera } \\
\text { (Pantanal parasitic Catfish) } \\
\text { Brachioica magdalenae/Paravandella phaneronema (Pencil Catfish) } \\
\text { Paracanthopoma parva } \\
\text { Plectrochilus diabolicus } \\
\text { Plectrochilus machadol } \\
\text { Plectrochilus saguineus } \\
\text { Plectrochilus wiener } \\
\text { Vandellia balzani } \\
\text { Vandellia beccarii } \\
\text { Vandellia cirrhosa (Candiru) }\end{array}$ \\
\hline Characidae (Piranha) & $\begin{array}{l}\text { Pygoristis denticulate/Serrasalmus denticulatus } \\
\text { (Golden Piranha/Big-toothed/Lobe-toothed Piranha) } \\
\text { Pygocentrus nattereri (Red/Red Bellied Piranha) } \\
\text { Pygocentrus cariba (Black Spot Piranha) } \\
\text { Serrasalmus sanchezi (Ruby-red/Ruby-red Throated Piranha) } \\
\text { Serrasalmus gibbus } \\
\text { Serrasalmus rhombeus } \\
\text { Serrasalmus spilopleura } \\
\text { Serrasalmus serrulatus } \\
\text { Pristobrycon striolatus } \\
\text { Metynnis argenteus (Silver Dollar) } \\
\text { Bramocharax bransfordii (Long Jaw tetra) }\end{array}$ \\
\hline Esocidae (Pike and Pickerel) & $\begin{array}{l}\text { Esox americanus (Redfin Pickerel) } \\
\text { Esox lucius (Northen Pile) } \\
\text { Esox masquinongi (M eskellunge) }\end{array}$ \\
\hline Electrophoridae & Electrophorus electricus (Electric Eel) \\
\hline
\end{tabular}

katak, udang bahkan mungkin dapat menyerang apa saja bila lapar. Walaupun langsing tetapi mulutnya sangat lebar sehingga ikan yang besarpun dapat dimakannya. Karena ukuran tubuhnya yang dapat menjadi besar terutama Aligator spatula yang dapat mencapai 1,5 meter tentu saja menakutkan.

- Electric eel atau belut listrik. M empunyai kapasitas daya listrik yang besar. Bisa mencapai 200 volt. Beberapa orang bisa tersengat terutama bila kena daerah ekornya dan dapat menimbulkan sakit sampai kematian. Tentu sangat berbahaya.

- Ikan buntal atau Puffer Fish. Ikan ini memang cantik bila dipandang, tetapi beracun, terutama bila dimakan. Dapat membesar, sebesar bola sepak bila terasa ada bahaya atau stres. Ikan ini juga termasuk karnivora sejati yang sangat ganas sebagai pemangsa (Robert, 1975). Bila masuk ke perairan tentu membuat ekosistem akan berantakan. Di Indonesia juga ada ikan buntal ini yaitu di Sungai Musi dan Sungai Batanghari, serta sungai-sungai besar di Kalimantan. Namun buntal ini kurang keganasannya dibanding yang dari Amazon.

Apabila ingin melihat ikan-ikan yang dilarang masuk dan ingin tahu wujud asli ikan-ikan tersebut sesuai dengan yang tertera dalam daftar peraturan Menteri Pertanian serta Menteri Kelautan dan Perikanan, maka dapat dilihat di Taman Mini Indonesia Indah tepatnya di Taman Akuarium Air Tawar, Dunia Air Tawar. Wahana ini mempunyai izin dari Menteri Kelautan dan Perikanan 
Republik Indonesia untuk mempertontonkan ikan-ikan tersebut dan hanya untuk dilihat tidak diperjualbelikan. Beberapa contoh gambar spesies ikan hias yang dilarang masuk ke Indonesia terlampir pada Lampiran 1.

\section{DAFTAR ACUAN}

Kottelat, M., Whitten, A.J., Kartikasari, S.N., \& Wirjoatmodjo, S. 1995. Freshwater Fishes of Western Indonesia and Sulawesi. Periplus Edituion (HK) Ltd. And Ministry of State for Population and Environtment Rep. of Indonesia, 293 pp.

Paysan, K. 1975. The country life guide to Aquarium Fishes. Country life books, 239 pp.
Patterson, C. 1982. Morphology and Interrelationships of Primitive Actinopterygian Fishes. American Zoologist, 22 pp.

Robert, T.R. 1975. Geographical distribution of Africant freshwater fishes. Zoological J. of the Linnean Society, $57 \mathrm{pp}$.

Satyani, D., Priyadi, A., Kadarini T., \& Subagya, J. 2002. Peningkatan keberhasilan kematangan gonad dan ovulasi ikan balashark (Balashark macracanthus). Laporan hasil riset perikanan air tawar tahun 2002. Balai Riset Perikanan Budidaya Ikan Air Tawar, $6 \mathrm{hlm}$. 
Lampiran 1. Beberapa contoh gambar spesies ikan hias yang dilarang masuk ke Indonesia

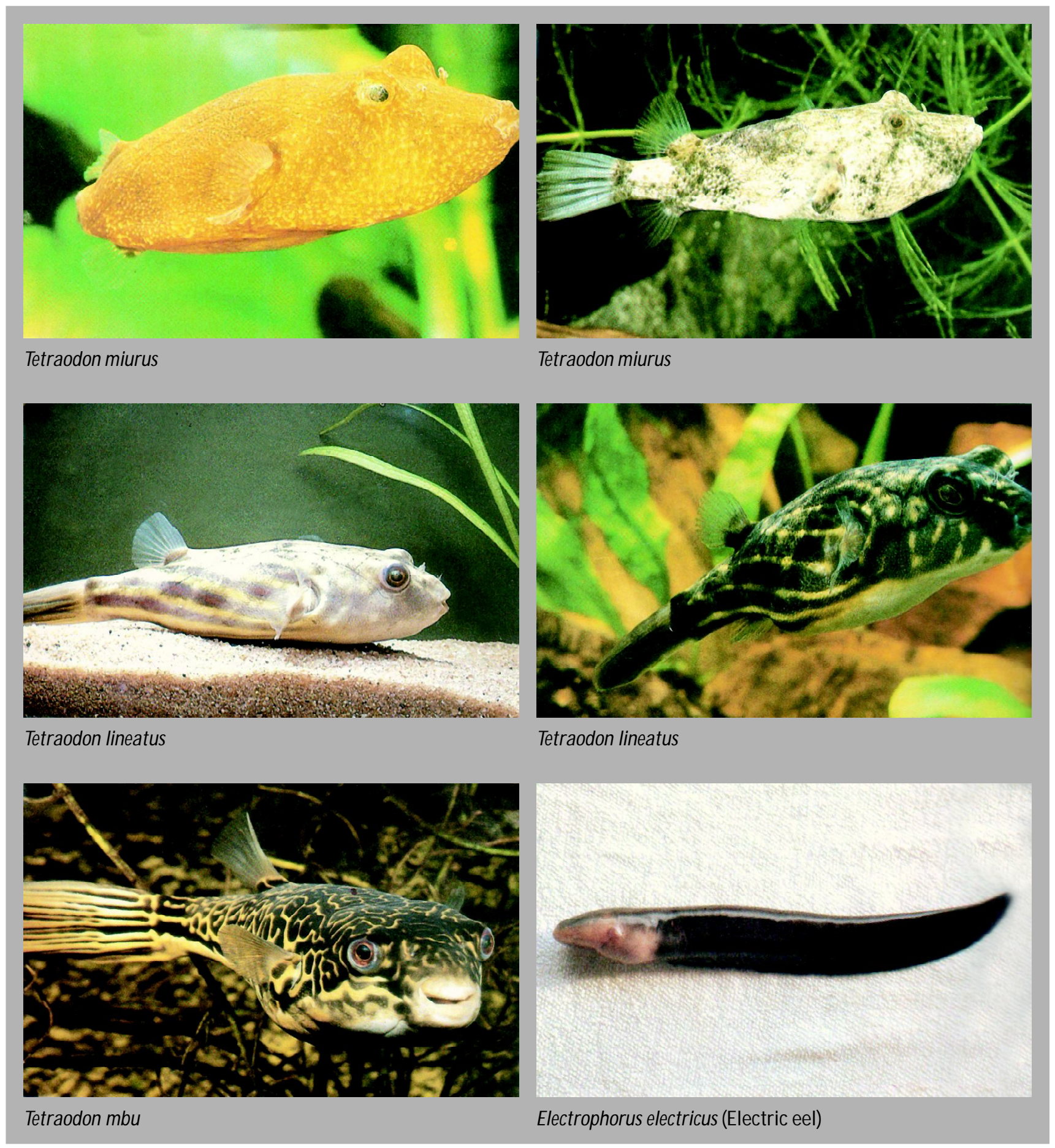




\section{Lanjutan Lampiran 1}
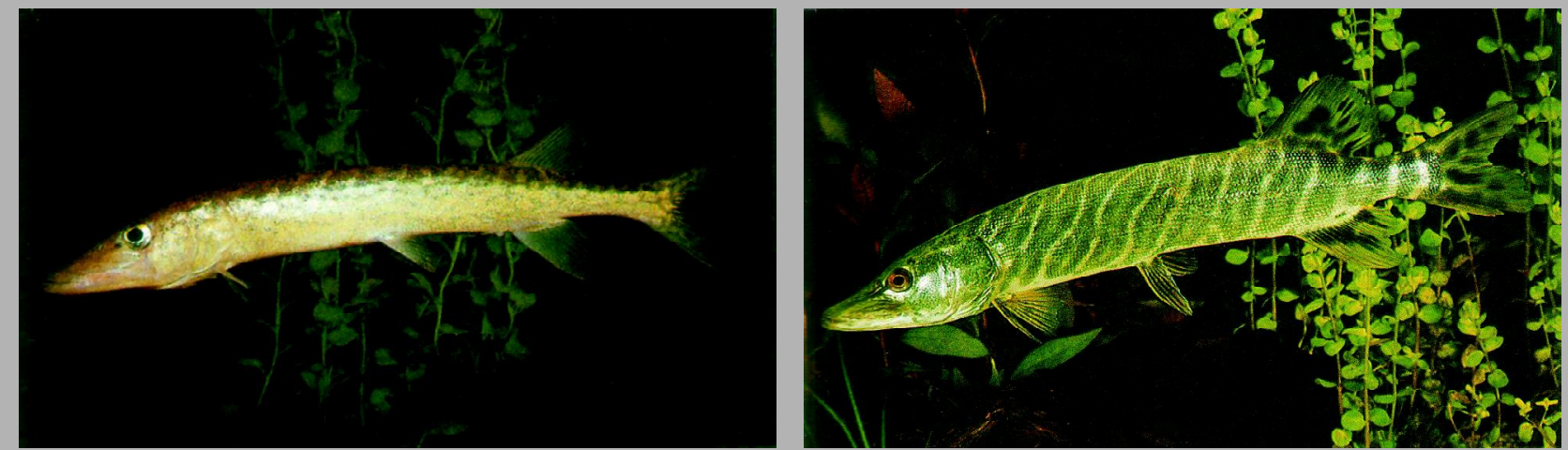

Esox americanus (Redfin Pickerel)

Esox lucius (Northen Pile)

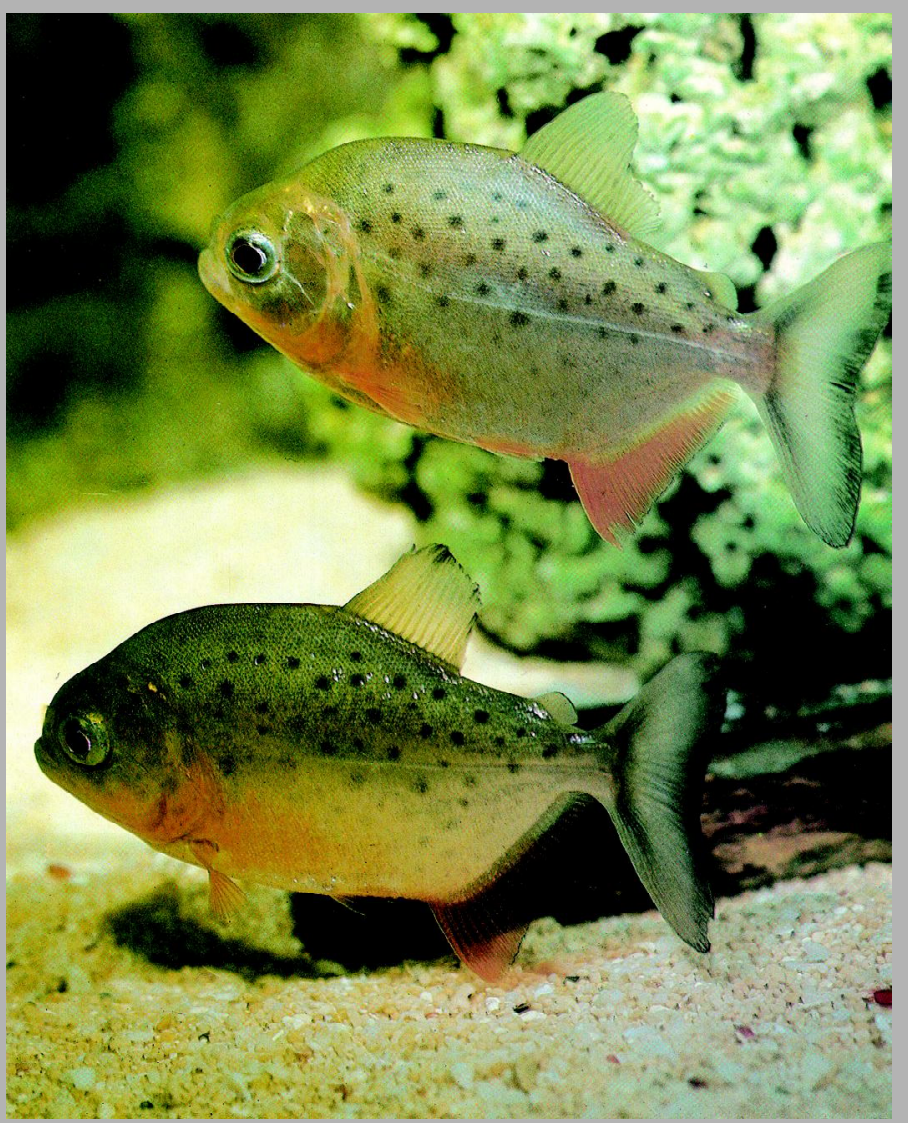

Serasalmus nattereri 


\section{Lanjutan Lampiran 1}
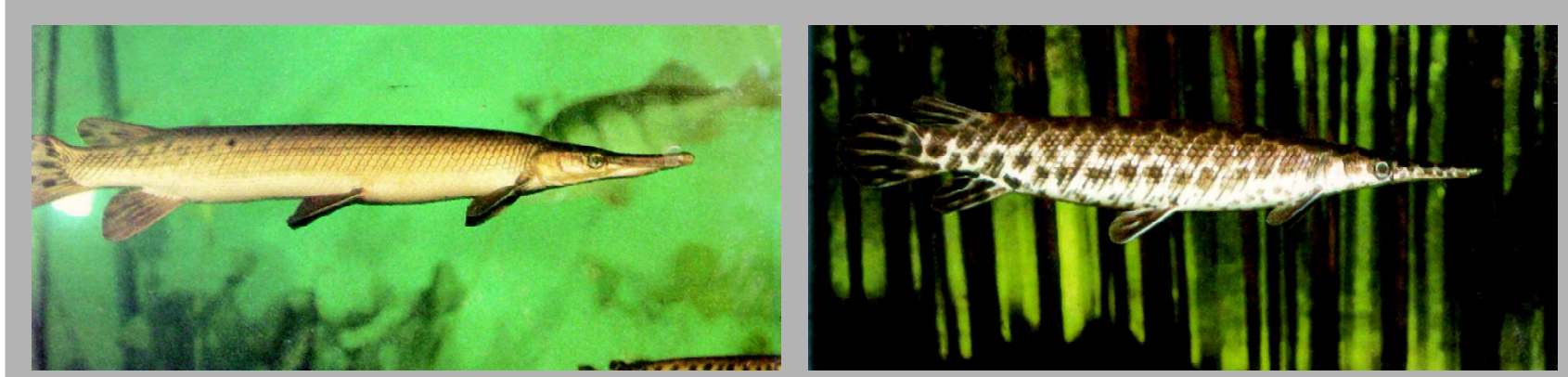

Aligator
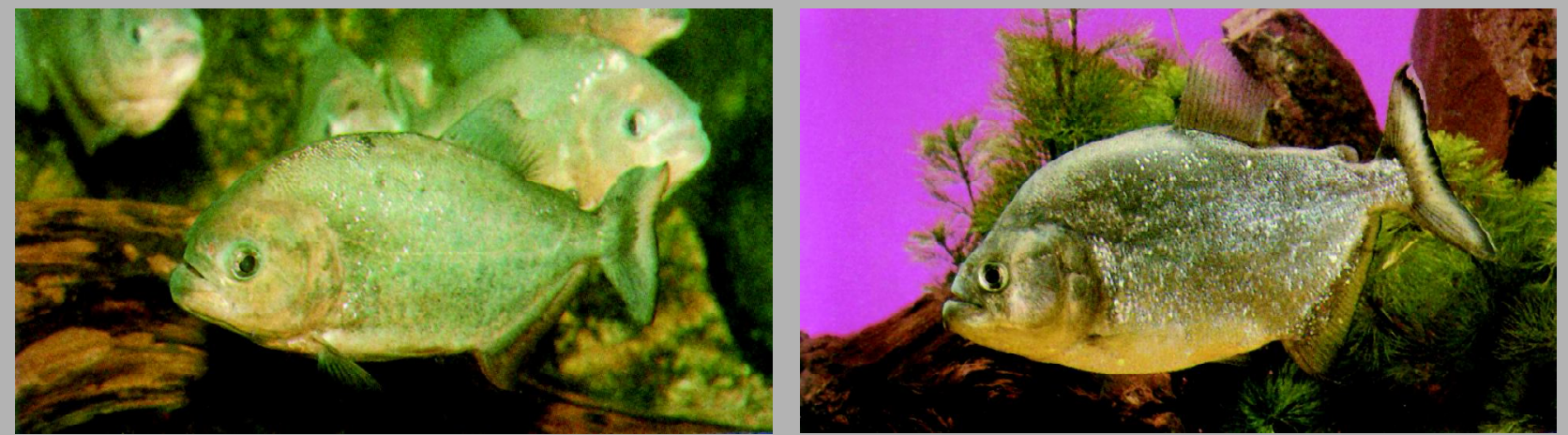

Serasalmus sanchez

Serasalmus gibbus
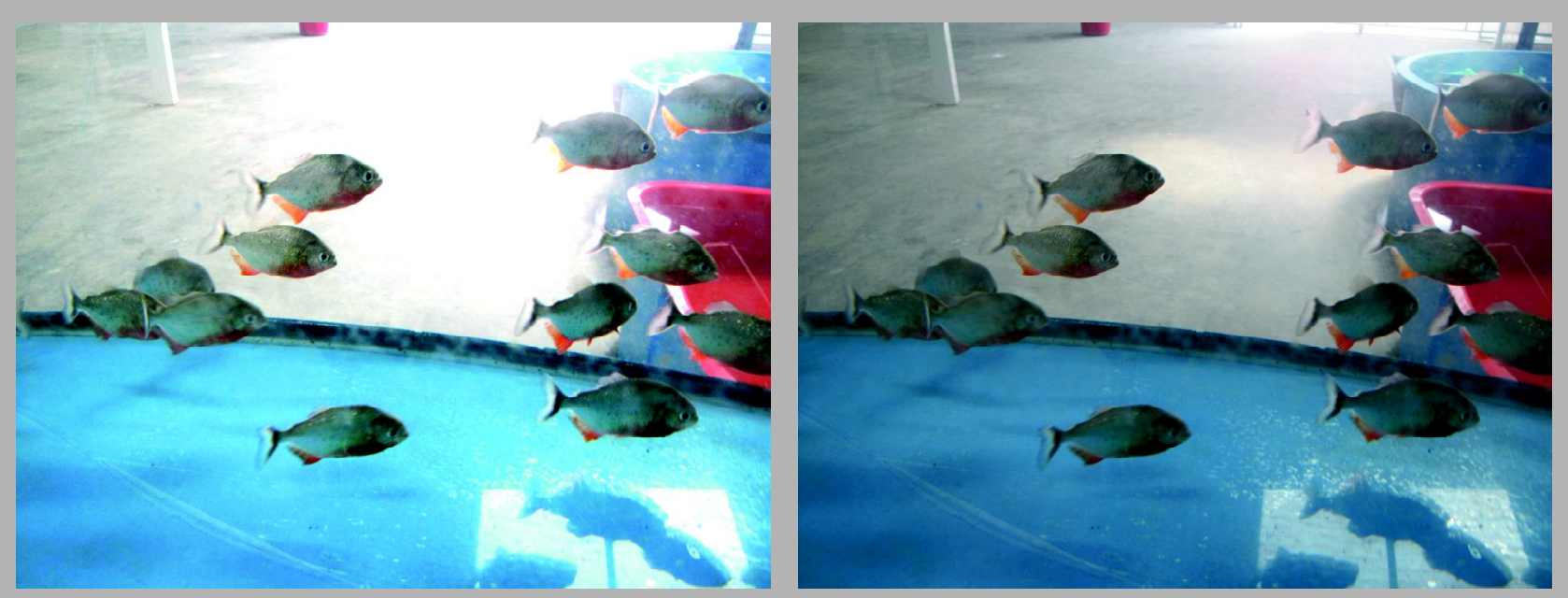

Serasalmus nattereri 